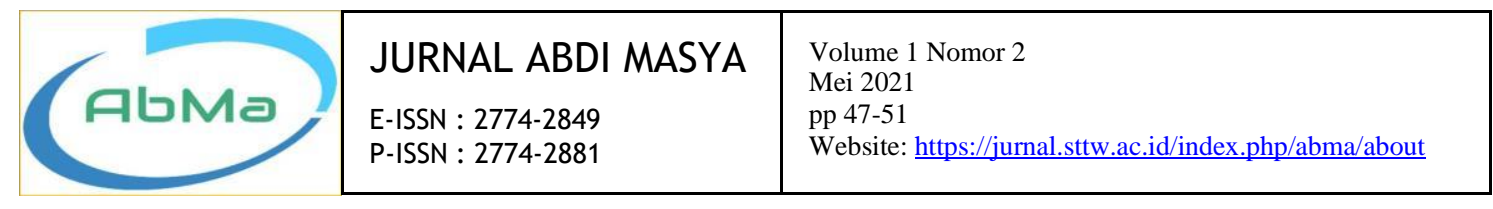

\title{
PELATIHAN PENGGUNAAN ALAT UJI EMISI GAS BUANG KENDARAAN BAGI TENAGA LABORAN SMK SE-KOTA DAN KABUPATEN PEKALONGAN
}

\section{TRAINING ON THE USE OF VEHICLE EXHAUST EMISSIONS TEST EQUIPMENT FOR SMK WORKERS IN CITIES AND DISTRICTS OF PEKALONGAN}

\author{
Imam Prasetyo ${ }^{1}$ \\ 1) Prodi Teknik Mesin Politeknik Muhammadiyah Pekalongan, Pekalongan, Indonesia \\ *E-mail: Imamprasetyo27@gmail.com
}

\begin{abstract}
ABSTRAK
Asisten laboratorium sekolah atau biasa disebut dengan toolman adalah salah satu pendidik yang penting. Merek sangat diperlukan untuk mendukung dan meningkatkan kualitas proses pembelajaran di sekolah. Oleh karena itu keberadaan asisten laboratorium di laboratorium sangat penting untuk menentukan prestasi akademik guru dan siswa. Untuk itu, asisten laboratorium harus memiliki hard skill dan soft skill yang memadai. Inisiatif, ketekunan, kreativitas, keterampilan dan teknik serta pengetahuan yang dikuasai oleh asisten laboratorium berkontribusi terhadap efisiensi dan efektivitas serta produktivitas laboratorium yang dikelola sekolah Tujuan diadakan dari kegiatan pengabdian masyarakat ini adalah dapat meningkatkan ketrampilan baik dalm teori maupun praktek praktek dalam menggunakan alat Uji Emisi Gas Buang kendaraan bermotor bagi tenaga laboran SMK serta menanbah wawasan tentang uji emisi gas buang kendaraan bermotor. Dalam kegiatan pengabdian masyarakat ini yang dikemas dalam bentuk pelatihan tentang penggunaan Alat uji emisi gas buang kendaraan yang di ikuti 12 Sekolah SMK dari sekolah SMK Se-kota dan Kabupaten pekalongan. Hasil dari pengabdian kepada masyarakat yang mengikuti pelatihan diharapkan para peserta bisa memahami menggunakan alat uji emisi gas buang sesuai dengan standar operasional prosedur merupakan capaian dari proses pengabdian ini. Hasil praktek peserta menggunakan alat uji emisi gas buang tersebut juga menunjukkan $85 \%$ peserta mendapatkan ilmu baru tentang penggunaan alat uji emisi gas buang kendaraan bermotor.
\end{abstract}

Kata Kunci: Pelatihan, Laboran, Emisi Gas Buang

\section{ABSTRACT}

The school laboratory assistant or commonly referred to as the tool man is an important educator. Brands were needed to support and improve the quality of the learning process in schools. Therefore, the existence of laboratory assistants in the laboratory is very important to determine the academic achievement of teachers and students. For that, laboratory assistants must have adequate hard skills and soft skills. Initiative, perseverance, creativity, skills, and techniques as well as knowledge mastered by laboratory assistants contribute to the efficiency and effectiveness, and productivity of school-managed laboratories. Discard motorized vehicles for vocational laboratory assistants and add insight into motorized vehicle exhaust emission testing. This community service activity was packaged in the form of training on the use of vehicle exhaust emission testing kits which are attended by 12 SMK schools from SMK schools in the city and Pekalongan Regency. It was hoped that the results of community service that participate in the training will be able to understand that using exhaust emission test kits following standard operating procedures is an achievement of this service process. The results of the practice of the participants using the exhaust emission test equipment also showed that $85 \%$ of the participants received new knowledge about the use of motorized vehicle exhaust emission test kits.

Keywords: Training, Laboratory Assistant, Exhaust Emissions

Submit : 1 Maret 2021, Accepted: 6 Mei 2021

Published: 28 Mei 2021 


\section{PENDAHULUAN}

Peningkatan jumlah penduduk yang dibarengi dengan peningkatan nilai konsumsi barang dan jasa yang berdampak pada kualitas lingkungan. Misalnya peningkatan kepemilikan kendaraan selalu diiringi dengan peningkatan emisi gas buang ke udara sehingga meningkatkan tingkat polusi. Sedangkan kebutuhan transportasi merupakan kebutuhan dasar masyarakat untuk menunjang mobilitas barang dan jasa guna meningkatkan kapasitas ekonomi masyarakat [1]. Oleh karena itu, pemerintah dituntut untuk menyediakan infrastruktur transportasi di sektor ini. Selain beban pencemaran kendaraan bermotor, gas pencemar yang dikeluarkan oleh sektor industri, rumah tangga dan kegiatan pembakaran sampah semakin menambah beban pencemar lingkungan yang dikeluarkan oleh kegiatan masyarakat [2]. Dengan kondisi seperti itu, bisa dibayangkan betapa berat beban pemerintah daerah dalam mengatasi masalah pencemaran udara [3].

Oleh karena itu tenaga pendidik dan kependidikan terutama di Sekolah Menegah Kejuruan mempunyai peranan penting ikut serta dalam memberikan pengetahuan tentang bahaya dari emisi gas buang yang nantinya bisa di sampaikan dalam proses pendidikan terutama saat mengajar. Hal ini disebabkan karena ada dimensi-dimensi proses pendidikan atau lebih khusus lagi proses pembelajaran yang diperankan oleh pendidik yang tidak bisa diganti oleh teknologi. Walaupun teknologi dapat dimanfaatkan dalam proses pembelajaran yang cepat, namun peranan pendidik lebih dominan. Begitu juga dengan tenaga kependidikan yang bertugas melaksanakan administrasi, pengelolaan, pengembangan, pengawasan, dan pelayanan teknis untuk menunjang proses pendidikan pada satuan pendidikan [4].

Standar Nasional Pendidikan menyatakan bahwa sekolahan seperti SMP/MTs atau bentuk lainnya sederajat dan SMK/SMA/MA atau bentuk lain yang sederajat sekurangkurangnya memiliki tenaga kependidikan yang terdiri atas kepala sekolah tenaga administrasi, tenaga perpustakaan, tenaga laboratorium, dan tenaga kebersihan sekolah [5]. Peraturan Menteri Pendidikan Nasional nomor 26 tahun 2008 tentang standar tenaga laboratorium sekolah menyebutkan bahwa standar tenaga laboratorium sekolah mencakup kepala laboratorium sekolah, teknisi laboratorium sekolah, dan laboran sekolah. Untuk dapat diangkat sebagai tenaga laboratorium sekolah, seseorang wajib memenuhi standar tenaga laboratorium sekolah yang berlaku secara nasional [6].

Tenaga laboran sekolah merupakan salah satu tenaga kependidikan yang sangat diperlukan untuk mendukung peningkatan kualitas proses pembelajaran di sekolah melalui kegiatan laboratorium. Oleh karena itu keberadaan laboran di suatu laboratorium sangatlah penting dalam menentukan keberhasilan akademik guru dan siswa. Untuk itu, Laboran seyogyanya memiliki hard skills dan soft skills yang memadai. Inisiatif, ketekunan, kreatifitas, kecakapan dan keterampilan serta pengetahuan yang dikuasai oleh Laboran, membantu efisiensi dan efektifitas serta produktivitas dari laboratorium yang dikelola oleh sekolahan. Maka dari itu Program Studi D3 Teknik Mesin di Politeknik Muhammadiyah Pekalongan mengadakan kegiatan pelatihan Penggunaan Alat Uji Emisi Gas Buang Kendaraan Bermotor Bagi Tenaga Laboran SMK Se-Kota dan Kabupaten Pekalongan guna membantu tenaga laboran meningkatkan ketrampilan praktek dan teori dalam menguasai penggunaan Alat Uji Emisi Gas Buang Kendaraan Bermotor, juga sebagai pengenalan Alat Uji Emisi Gas Buang Kendaraan bagi SMK yang belum mempunyai alat uji emisi gas buang kendaraan bermotor.

\section{METODE}

Kegiatan ini dilakukan dalam dua materi, yaitu materi pertama tentang dampak atau bahaya dari emisi gas buang yang dihasilkan dari kendaraan bermotor, kemudian materi kedua di isi tentang pengenalan alat uji emisi gas buang dan cara menggunakan alat uji emisi gas buang kendaraan sesuai SOP. Proses kegiatan pengabdian masyarakat ini dilakukan dengan pembelajaran di ruang kelas dan laboratorium teknik mesin dalam bentuk ceramah, praktek dan tanya jawab. Setelah materi tentang pengenalan alat uji emisi gas buang dan cara menggunakan alat uji emisi gas buang kendaraan diberikan kepada peserta, lalu peserta diberikan waktu untuk 
mencoba menggunakan alat uji emisi gas buang sesuai dengan petunjuk yang sudah diberikan di awal materi dengan tujuan agar peserta langsung mempraktekkan dan memahami secara langsung dalam menggunakan alat uji emisi gas buang kendaraan bermotor

Uraian kegiatan pengabdian masyarakat dalam bentuk pelatihan ini, pelaksanaannya dibagi menjadi beberapa tahap yaitu Tahap I : Pendekatan kepada mitra untuk mengidentifikasi permasalahan, tujuan yang ingin di capai. Tahap II : Melakukan kontrak waktu dengan mitra untuk kegiatan pengabdian masyarakat ini dalam bentuk pelatihan penggunaan alat uji emisi gas buang. Tahap III : Pemberian teori mengenai prosedur penggunaan alat uji emisi gas buang dan kemudian lanjut praktek pelatihan penggunaan alat uji emisi gas buang. Tahap IV : Evaluasi kegiatan dan penyusunan rencana tindak lanjut.

\section{HASIL DAN PEMBAHASAN}

Dalam kegiatan pengabdian masyarakat ini yang dikemas dalam bentuk pelatihan tentang penggunaan Alat Uji Emisi Gas Buang Kendaraan Bermotor Bagi Tenaga Laboran SMK SeKota dan Kabupaten Pekalongan, yang di ikuti oleh hampir 75\% dari sekolah SMK Se-kota dan Kabupaten pekalongan. Pada saat pelaksanaan kegiatan terlihat antusiasme para peserta dengan berbagai pertanyaan yang dilontarkan oleh para peserta tentang penggunaan alat uji emisi gas buang kendaraan bermotor. Dari hasil praktek peserta bisa memahami menggunakan alat uji emisi gas buang sesuai dengan standar operasional prosedur merupakan capaian dari proses pengabdian ini. Hasil praktek peserta menggunakan alat uji emisi gas buang tersebut juga menunjukkan seberapa besar ilmu baru yang telah diperoleh tentang penggunaan alat uji emisi gas buang kendaraan bermotor. Kegiatan pelatihan yang diselenggarakan selama satu hari, mendapat sambutan dan respon yang baik dari para peserta maupun dari pihak sekolah SMK yang mengirimkan tenaga laborannya dalam kegiatan ini. Keadaan ini dapat dilihat dari kehadiran peserta yang cukup memenuhi di ruang kelas dan laboratorium Teknik Mesin Politeknik Muhammadiyah Pekalongan.

Namun dalam setiap kegiatan pengabdian masyarakat pasti ada kelebihan dan kekurangannya, untuk kelebihan dari kegiatan ini alhamdulilah diantaranya $100 \%$ materi dapat terserap kepada peserta pelatihan dengan baik, $100 \%$ peserta bisa mengoperasikan penggunaan alat uji emisi gas buang dengan baik sesuai SOP, $85 \%$ peserta melakukan umpan balik dengan mengajukan pertanyaan terkait penggunaan alat uji emisi. Untuk kekurangan dari kegiatan ini media atau alat uji emisi gas buang hanya ada satu unit alhasil peserta untuk mencoba mengoperasikan alat uji emisi satu persatu butuh waktu dan antri sehingga kurang efisien dalam waktu.

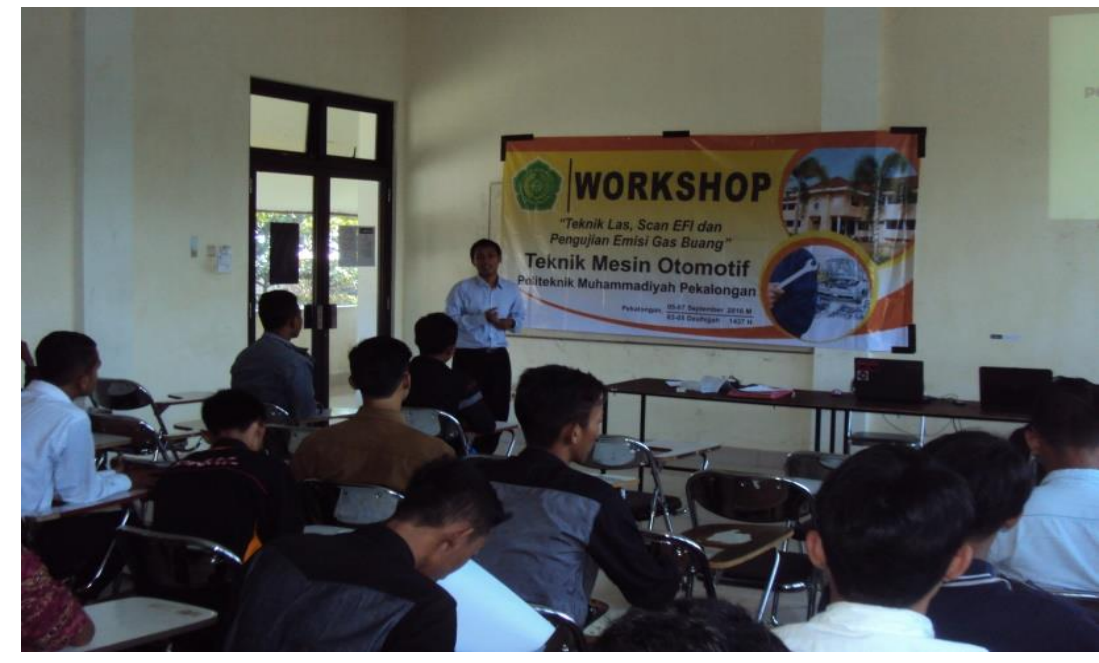

Gambar 1. Penyampaian materi teori tentang penggunaan alat uji emisi gas buang 


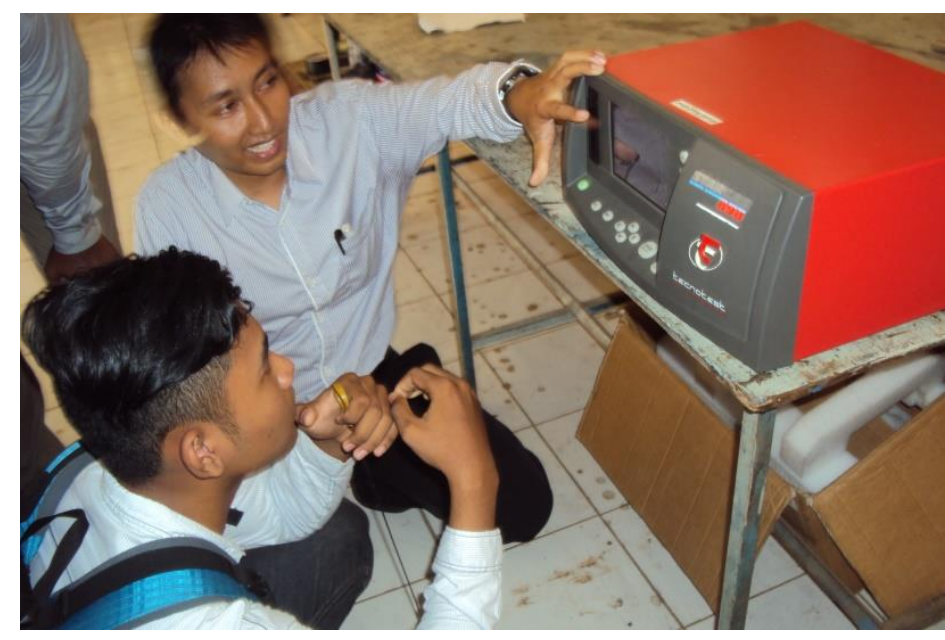

Gambar 2. Proses mengoperasikan alat uji emisi dan melibatkan peserta

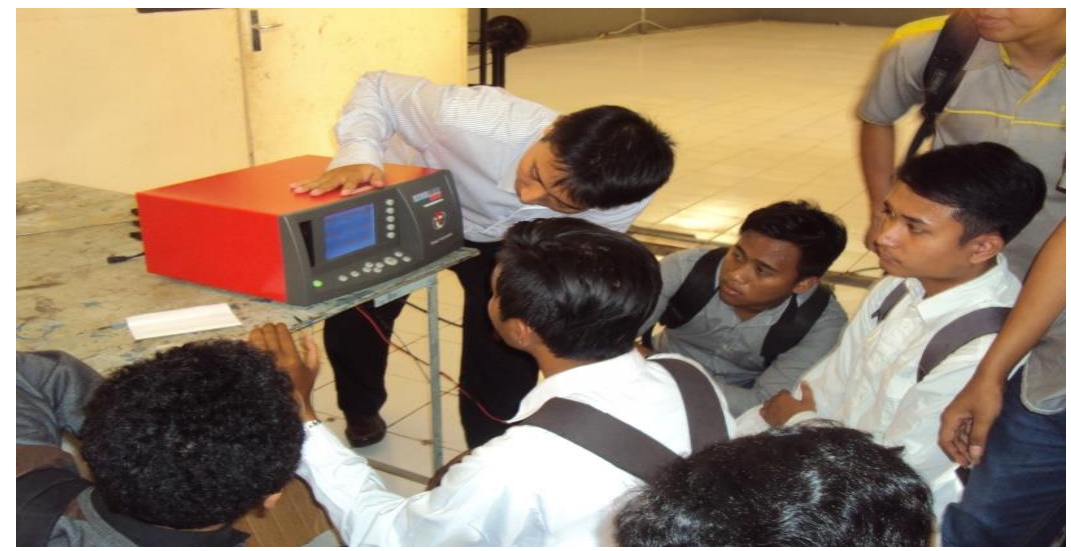

Gambar 3. Peserta mencoba mengoperasikan alat uji emisi gas buang sesuai SOP

Gambar 1-3 menggambarkan proses kegiatan pelatihan penggunaan alat uji emisi gas buang yang dimulai dari pembekalan secara teoritis materi tentang penggunaan alat uji emisi gas buang sesuai dengan SOP kemudian dilanjut dengan praktek penggunaan alat uji emisi gas buang dan peserta diharuskan untuk mencobanya satu persatu agar bisa mengoperasikan alat uji emisi. Selesai pelatihan peserta dibekali buku petunjuk pengoperasian alat uji emisi gas buang sesuai dengan SOP yang berlaku.

\section{KESIMPULAN}

Dalam kegiatan Pengabdian kepada masyarakat berupa pelatihan penggunaan alat uji emisi gas buang kendaraan bermotor bagi tenaga laboran SMK Se-kota dan Kabupaten Pekalongan, dapat diambil beberapa kesimpulan antara lain:

1. Dengan adanya pelatihan ini dapat menambah ketrampilan praktek dan teori dalam menggunakan alat Uji Emisi Gas Buang kendaraan bermotor bagi tenaga laboran SMK.

2. Meningkatkan wawasan tenaga laboran SMK tentang uji emisi gas buang kendaraan bermotor.

3. Membantu memberikan pengetahuan tentang bahaya dari emisi gas buang yang dihasilkan dari kendaraan bermotor sekaligus memperkenalkan alat uji gas buang bagi SMK yang belum mempunyai alat uji emisi gas buang kendaraan. 


\section{DAFTAR PUSTAKA}

[1] W. Wahab, N. La Nafie, M. Ramang, I. Raya, and Y. Hala, Pelatihan Pengukuran Emisi Gas Karbon Monoksida (CO) dan Nitrogen Oksida (NOx) pada Kendaraan Bermotor di SMA Negeri 2 Bone, Panrita Abdi, vol. 3, no. 2, pp. 125-132, 2019.

[2] I. Chahaya, "Dampak Emisi Gas Buang Terhadap Kesehatan dan Lingkungan," Fakultas Kesehatan Masyarakat, Universitas Sumatra Utara, 2015.

[3] A. Mattimu, A and E.W. Fardial, "Pengetahuan Lingkungan Edisi 7," Jurusan Biologi., Fakultas MIPA, Universitas Hasanudin Makasar. 2008.

[4] S. Akhmad, Pengantar Manajemen Sumber Daya Manusia. Jakarta: Prestasi Pustakarya, 2012.

[5] H. Hidayati, "Manajemen Pendidikan, Standar Pendidik, Tenaga Kependidikan, dan Mutu Pendidikan," Al-Ta lim J., vol. 21, no. 1, pp. 42-53, 2014.

[6] H. Sukirman, "Manajemen Tenaga Kependidikan," in Bahan Ajar, Yogyakarta: FIP, Universitas Negeri Yogyakarta, 2000. 